\title{
Characterization of Candida Species Isolated from Cases of Lower Respiratory Tract Infection among HIV/AIDS Patients in Calabar, Nigeria*
}

\author{
Ofonime Mark Ogba ${ }^{1}$, Lydia Nyong Abia-Bassey², James Epoke², Baki Idasa Mandor ${ }^{1}$, \\ Godwin Dickson Iwatt ${ }^{3}$ \\ ${ }^{1}$ Department of Medical Microbiology/Parasitology, University of Calabar Teaching Hospital, Calabar, Nigeria; ${ }^{2}$ Department of \\ Medical Laboratory Science, University of Calabar, Calabar, Nigeria; ${ }^{3}$ Department of Microbiology, University of Calabar, Calabar, \\ Nigeria. \\ Email: ofonimemark@yahoo.com
}

Received June $2^{\text {nd }}, 2013$; revised July $2^{\text {nd }}, 2013$; accepted August $2^{\text {nd }}, 2013$

Copyright (C 2013 Ofonime Mark Ogba et al. This is an open access article distributed under the Creative Commons Attribution License, which permits unrestricted use, distribution, and reproduction in any medium, provided the original work is properly cited.

\begin{abstract}
This study was designed to identify and characterize the Candida species isolated from lower respiratory tract infections among HIV positive patients and to determine the prevalence rates of Candida infections among these subjects. Two early morning expectorate sputum samples were collected from 272 HIV positive subjects visiting the ART clinics and DOTS centre with cases of lower respiratory tract infection, over a period of 14 months from May 2009 to July 2010 in Calabar. Subjects were recruited for this study upon approval by the Ethical Research Committee of the University of Calabar Teaching Hospital and obtaining written informed consent from the patients. Samples were processed by standard methods for isolation of Candida. Speciation was done by a germ tube test, chlamydospore production on corn meal agar and sugar fermentation and assimilation tests using the Microexpress Candida identification kit (Tulip, India). Out of the 544 sputum samples collected from 272 subjects, Candida species were isolated from 40 (14.7\%) and identified after confirming the growth in the second sample. The majority of Candida species among the Candida isolates were Candida albicans (80\%) followed by Candida tropicalis 5 (12.5\%), Candida dubliniensis 2 (5.0\%) and Candida guilliermondii 1 (2.5\%). The isolation rate of Candida species from sputum samples was found to be highest among subjects aged 25 - 34 years, followed by those aged 15 - 24 years. Twenty (7.3\%) HIV seropositive subjects had bacterial infections, while 4 (1.5\%) subjects had mixed fungal and bacterial infections. This study is the first of its kind to be carried out in Calabar and the South-South geopolitical region of Nigeria, and has shown that pulmonary candidiasis is a health problem among HIV positive patients in Calabar.
\end{abstract}

Keywords: Candida Infections; Pulmonary; HIV/AIDS; Characterization

\section{Introduction}

Candida is a polymorphic fungus. It is a Gram positive, oval, budding yeast cell that produces pseudohyphae both in culture and in tissues and exudates [1]. They exhibit filamentous mycellial morphology in the saprophytic phase, but have typical yeast morphology in the parasitic phase, in tissue and when grown at $37^{\circ} \mathrm{C}$ in the laboratory [1]. They form pseudohyphae when the buds continue to grow but fail to detach, producing chains of elongated cells that are pinched or constricted at the septations between cells [2]. At temperatures below $26^{\circ} \mathrm{C}$ in nutritionally poor media such as cornmeal agar, it produces thick-

\footnotetext{
${ }^{*}$ Conflicts of Interests: None declared.
}

walled resting cells 7 to $17 \mathrm{~mm}$ in diameter, called chlamydospores [3]. It is a member of the normal flora of the mucous membranes in the gastrointestinal, upper respiratory and female genital tracts [4].

There are about 68 species of Candida, the most pathogenic is C. albicans [5]. The other non-albicans Candida (NAC) species include C. dubliniensis, C. glabrata, C. guilliermondii, C. tropicalis, C. parapsilosis, C. krusei and C. hisitaniae, C. kefyr, C. lipolytic and C. pelliculos $[6,7]$.

Candida pneumonia is one of the most challenging of all the Candida infections. Primary Candida pneumonia refers to infections limited to the lungs, while secondary Candida pneumonia indicates lung involvement due to 
the movement of invasive Candida from other areas of the body [5]. The criteria for the diagnosis of pulmonary candidiasis are still controversial. The isolation of Candida from culture of sputum, endotracheal aspirates, bronchoscopic samples, percutaneous lung needle aspirates and even from lung tissue may only represent colonization of the trachea-bronchial tree [4]. Despite the debate about the diagnosis of pulmonary candidiasis, the definitive diagnosis is still resting on histological demonstration of the yeast in lung tissue with associated inflammatory changes at autopsy $[7,8]$.

The increase in the number of immunocompromised patients during the last few decades, as a result of chemotherapy or HIV/AIDS has resulted in a parallel increase in the number of opportunistic infections, especially those due to Candida species $[9,10]$.

Rapid identification and speciation of Candida species are essential in clinical laboratories. However, no single phenotypic test is highly effective in identifying Candida species and the combination of tests is sometimes necessary for identification. Molecular techniques have been employed to characterize Candida spp. Although sensitive and specific it is not cost effective for routine clinical mycology laboratories in a resource constrained setup like ours [11].

\section{Aims and Objectives}

The aim of the study was to determine the rate of isolation of Candida species from sputum samples of HIV positive patients with respiratory symptoms, to identify and characterize the Candida species using various phenotypic methods such as Germ tube test, Chlamydospore production and identification to specie level with Microxpress Candida identification kit (Tulip diagnostic LTD, India), according to the manufacturer's instructions.

\section{Materials and Methods}

\subsection{Study Sites and Subjects Selection}

The present study was carried out in the department of Microbiology/Parasitology, University of Calabar Teaching Hospital, Calabar. Subjects were recruited from two tertiary hospitals; the University of Calabar Teaching Hospital and Lawrence Henshaw Hospital located in Calabar municipality and Calabar south local Government areas respectively. The cases selected for the study included HIV positive subjects with respiratory symptoms who were able to produce sputum. Sputum samples showing less than 10 squamous epithelial cells and 25 or more polymorphonuclear leukocytes per low power field $(100 \times)$ were included in this study.

\subsection{Collection and Examination of Samples}

A total of 272 sputum samples in duplicates were collected from May 2009 to July 2010 from the subjects. All sputum specimens were processed by Gram staining, $10 \%$ $\mathrm{KOH}$ mount, culture, germ tube test, detection of chlamydospore and sugars fermentation and assimilation tests. A $10 \% \mathrm{KOH}$ mount of sputum sample showing plenty of Candida pseudohyphae were considered as potential pathogens and not as colonizers. The isolates were considered significant by correlation with microscopy and growth of two consecutive cultures. The Candida species were isolated repeatedly in pure culture from two consecutive early mornings expectorate sputum samples [4]. Speciation of Candida was by germ tube test, morphology on corn meal agar, sugar fermentation and assimilation tests using Microexpress Candida identification kits (Tulip, India) according to the manufacturer's instructions [4,12].

\subsection{Direct Examination of the Specimens}

\subsubsection{Gram Stain}

Smears made from the most purulent: or mucopurulent part of the sputum. Smears were examined for the presence of gram positive budding yeast cells with pseudohyphae. Specimen was considered as acceptable when 25 or more polymorphonuclear leukocytes were seen per low power field $(100 \times)$ with few (less than 10$)$ squamous epithelial cells.

\subsubsection{KOH Mount}

Smears were prepared for each sample by adding a loop full of sputum to a drop of $10 \% \mathrm{KOH}$ on a clean, greasefree slide and placing a cover slip over it. The preparations were slightly warmed to digest the materials and examined under the microscope with X10 and X40 objective for yeast cells, pseudohyphae [12].

\subsubsection{Culture}

The most bloody, purulent, or mucus laden portions of sputum samples were inoculated on Sabouraud Dextrose Agar (SDA) with and without chloramphenicol (16 $\mu \mathrm{g} \cdot \mathrm{ml}^{-1}$ ) in duplicates incubated at $37^{\circ} \mathrm{C}$ and $25^{\circ} \mathrm{C}$. Cultures were examined every other day for growth up to 2 weeks before discarding as negative $[12,13]$. The macroscopic features of the growth were opaque pasty glabrous or membranous texture often with the sweet smell, reminiscent of ripe apples. The growth was confirmed by observing the characteristic budding with pseudohyphae in the Gram stain [10]. Pure cultures of every isolate were prepared before performing any physiological test. This was done by sub-culturing individual isolates onto fresh SDA plates and incubating at $37^{\circ} \mathrm{C}$ and at room tempe- 
rature $\left(25^{\circ} \mathrm{C}-28^{\circ} \mathrm{C}\right)$ for 24 - 48 hours [12]. Any significant bacterial growth from SDA without chloramphenicol was purified on Cystein Lactose Electrolyte Deficient (CLED) agar, for further biochemical analysis and identification [13]. Identification of isolates was based on gross morphological characteristics, detailed study of stained samples and biochemical tests [14].

\subsection{Identification of Candida Isolates}

\subsubsection{Germ Tube Test}

All presumptive Candida species were subjected to germ tube test. Colonies from the purity plate were picked to perform the germ tube test. Small test tubes containing about $0.5 \mathrm{ml}$ human serum were inoculated with colonies of test organisms in batches of three replicates per test. Each batch included a known positive and negative control. Inoculated tubes were incubated at $37^{\circ} \mathrm{C}$ for $2-3$ hours. At the end of incubation, a drop of each serum was transferred to a clean slide, and a cover slip placed over it. These slides were examined microscopically under high power $(\times 40)$ objective to detect the presence of germ tubes, which are short hyphal initials $[4,9]$.

\subsubsection{Chlamydospore Formation}

All Candida isolates were tested for the production of chlamydospores in corn meal agar (CMA) with $1 \%$ Tween 80. Subcultures on corn meal agar plates, was made from SDA purity plate by furrowing the CMA plates (cut streak method), and incubating at room temperature $\left(25^{\circ} \mathrm{C}\right.$ $28^{\circ} \mathrm{C}$ ) for 2 - 5 days after which they were examined for the production of thick-walled chlamydospores in a lactophenol cotton blue mount of samples taken from the furrows of the corn meal agar plates $[4,15]$.

\subsubsection{Sugar Fermentation Test}

All Candida isolates were subjected to carbohydrate fermentation and utilization test using Candida identification kit, Tulip Diagnostics Limited, India. Each kit contained sterile media for colorimetric identification using biochemical test and carbohydrate utilization tests based on the principle of $\mathrm{pH}$ change and substrate utilization designed to identify various metabolic properties of different Candida species, that can be used to differentiate even closely related Candida species. The media were inoculated by adding $100 \mu \mathrm{l}$ of the Candida suspension, incubated at $20^{\circ} \mathrm{C}-25^{\circ} \mathrm{C}$ and read after 24 - 48 hours incubation. The Candidal suspension was prepared by purifying on a Brain Heart Infusion Agar (BHIA) medium, after which a single discrete colony was picked up and streaked on to BHI agar slant for enrichment and incubated at $20^{\circ} \mathrm{C}-25^{\circ} \mathrm{C}$ (room temperature) for $24-48$ hours. The growth on the slant was washed with 2 - $3 \mathrm{ml}$ of sterile saline and the turbidity of the suspension compared with Mcfarland standard number 5. The results were interpreted as per the standards given in the result interpretation chart.

\section{Results}

A total of 272 sputum samples were collected from all the HIV positive subjects enrolled during the study. Out of which 40 (14.7\%) Candida species were isolated and identified after confirming the growth in the second sample. The majority of Candida species among the Candida isolates were Candida albicans (80\%) followed by Candida tropicalis 5 (12.5\%), Candida dubliniensis 2 (5.0\%) and Candida guilliermondii 1 (2.5\%) (Table 1).

The isolation rate of Candida species from sputum samples was found to be highest among subjects aged 25 - 34 years, followed by those aged $15-24$ years. No Candida species were isolated from subjects aged 65 - 74 years (Table 2). Table 3 shows the prevalence of bacterial pathogens amongst the subjects. Twenty (7.3\%) HIV seropositive subjects had bacterial infections. Out of which 11 (4.0\%) were infected with Klebsiella pneumoniae, 6 (2.2\%) with Pseudomonas aeruginosa and 3 (1.1\%) with Proteus specie.

Table 4 shows the distribution of polymicrobial infections among the HIV-positive subjects. Out of the 4 (1.5\%) subjects with mixed infections, 3 (75.0\%) had Candida albicans and Klebsiella pneumoniae infections, while one subject (25.0\%) had Klebsiella pneumoniae \& Candida tropicalis infection.

Table 5 shows the specific characteristics of isolates of Candida species established with Microxpress Candida identification kit (Tulip diagnostics LTD, India).

\section{Discussion}

The diagnosis of pulmonary candidiasis is difficult not because it is difficult to demonstrate the organism in clinical samples but because isolation of Candida species in sputum does not necessarily mean that a person is suffering from pulmonary candidiasis. A good clinical cor-

Table 1. Distribution of Candida isolates among subjects.

\begin{tabular}{ccc}
\hline Candida species & $\begin{array}{c}\text { No of isolates } \\
(\mathrm{n}=272)\end{array}$ & $\begin{array}{c}\text { Percentage of } \\
\text { isolates (\%) }\end{array}$ \\
\hline Candida albicans & 32 & 80 \\
Candida tropicalis & 5 & 12.5 \\
Candida dubliniensis & 2 & 5.0 \\
Candida guilliermondii & 1 & 2.5 \\
Total & 40 & 14.7 \\
\hline
\end{tabular}


Table 2. Age and gender distribution of Candida species among subjects.

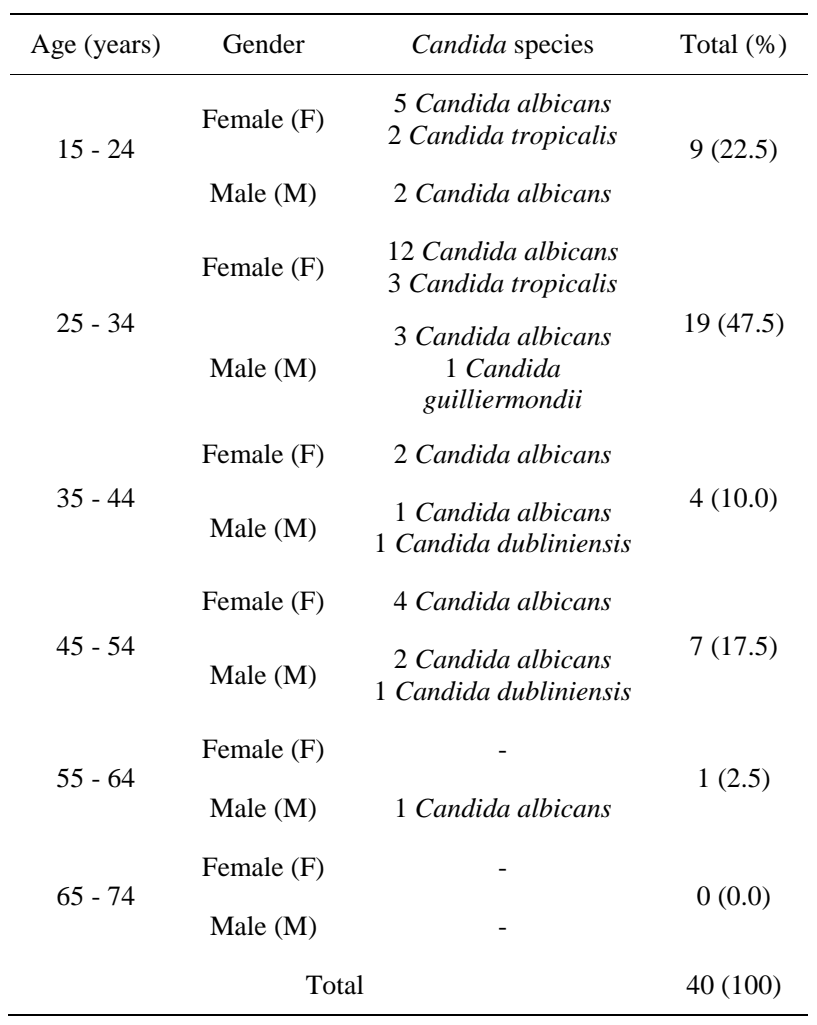

Denotes no Candida species was isolated.

Table 3. Distribution of bacterial pathogens from sputum samples of subjects.

\begin{tabular}{cc}
\hline Bacteria pathogens & No of isolates $(\mathrm{n}=272)$ \\
\hline K. pneumonia & $11(4.0)$ \\
P. aeruginosa & $6(2.2)$ \\
Proteus specie & $3(1.1)$ \\
Total & $20(7.3)$ \\
\hline
\end{tabular}

Table 4. Polymicrobial isolation from HIV positive subjects.

\begin{tabular}{cc}
\hline Types of isolates & $\begin{array}{c}\text { No of isolates (\%) } \\
(\mathrm{n}=272)\end{array}$ \\
\hline Candida albicans \& Klebsiella pneumonia & $3(75.0)$ \\
Candida tropicalis \& klebsiella pneumonia & $1(25.0)$ \\
Total & $4(1.5 \%)$ \\
\hline
\end{tabular}

relation is therefore necessary to ascertain the clinical significance of the isolate [4].

The total number of Candida species isolated during the study was 40 (14.7\%). These is higher than the $12.1 \%$ prevalence reported in India by Jha et al. [3], but considerably lower than $48 \%$ prevalence reported in New York,
USA by Diaz-Fuentes et al. [7]. The low prevalence rate of candidiasis recorded in this study as compared to the 48\% reported in America could have been due to the fact that Diaz-Fuentes et al. [7] recovered the Candida isolates at autopsy from lung tissues which is a definitive diagnostic technique for pulmonary candidiasis. It is likely that none of their isolates were lost. Candida species generally remains the most implicated opportunistic fungal pathogen in HIV/AIDS infection probably because it is an endogenous opportunist.

Candida albicans were found to be the most common species with 32 (80\%) isolates. This was followed in descending order of prevalence by C. tropicalis 5 (12.5\%), C. dubliniensis 2 (5.0\%) and C. guilliermondii 1 (2.5\%) (Table 1). Aluyi et al. [16] in Edo state, Nigeria found the distribution of Candida species among patients to be as follows: C. albicans (49.3\%), C. stellatoidea (25.4\%) and C. parapsilosis (25.3\%). A multicenter surveillance study conducted in Quebec, Canada in 2001 reported a distribution pattern for Candida as follows: C. albicans (64\%), C. tropicalis (17\%), C. parapsilosis (8\%), C. glabatra (6\%) and C. krusei (2\%) [17]. The findings of the present study are different from the above studies. This could be due to variation in geographical distribution of various Candida species.

The isolation rate of Candida species from sputum samples was found to be highest among subjects aged 25 - 34 years, followed by those aged 15 - 24 years. No Candida species were isolated from subjects aged 65 - 74 years (Table 2). Jha et al. [3], found the isolation rates of Candida species highest among subjects in the seventh decade of life followed by the fourth and fifth decade. In this study, the high prevalence of Candida species among subjects in the second and third decade of life could be attributed to the high sexual activity of subjects in this age group which leads to high HIV/AIDS transmission with resultant immunosuppresion and opportunistic infections which include Candida infections.

Bhalla [18] noted that pneumonia of bacterial origin occur at a rate many times higher in the HIV infected patients than in the general population. In this study, the $20(7.3 \%)$ prevalence of bacterial isolates is lower than the $44.28 \%$ reported in Hyderabad by Shailaja et al. [19], with $K$. pneumoniae as the most prevalent etiologic agent. This study also encountered $K$. pneumoniae as the most prevalent bacterial agent. Tchamran [20] in his study on lung diseases of bacterial origin in HIV infected individuals in African adults, noted that $81 \%$ of infections were due to $S$. pneumoniae and reported it to be the most offending pathogen in HIV reactive patients. The difference in prevalence rates may be ascribed to the types of culture media used during the present study. Sabouraud Dextrose Agar was the primary isolation medium. Streptococcus pneumoniae and other fastidious organisms do 
Table 5. Characterization of Candida species with Microxpress Candida identification kit.

\begin{tabular}{|c|c|c|c|c|c|c|c|c|c|c|c|}
\hline SPECIES & $\begin{array}{c}\text { Urease } \\
\text { utilisation }\end{array}$ & $\begin{array}{l}\text { Melibose } \\
\text { utilisation }\end{array}$ & $\begin{array}{c}\text { Lactose } \\
\text { utilization }\end{array}$ & $\begin{array}{c}\text { Maltose } \\
\text { utilization }\end{array}$ & $\begin{array}{c}\text { Sucrose } \\
\text { utilization }\end{array}$ & $\begin{array}{l}\text { Galactose } \\
\text { utilization }\end{array}$ & $\begin{array}{l}\text { Cellobiose } \\
\text { utilisation }\end{array}$ & $\begin{array}{c}\text { Inositol } \\
\text { utilization }\end{array}$ & $\begin{array}{c}\text { Xylose } \\
\text { utilization }\end{array}$ & $\begin{array}{c}\text { Dulcitol } \\
\text { utilization }\end{array}$ & $\begin{array}{l}\text { Raffinose } \\
\text { utilization }\end{array}$ \\
\hline C. albicans & - & - & - & + & - & + & - & - & + & - & - \\
\hline $\begin{array}{c}\text { C. } \\
\text { dubliniensis }\end{array}$ & - & - & - & + & - & + & - & - & $\mathrm{V}$ & - & - \\
\hline C. tropicalis & - & - & - & + & + & $\mathrm{V}$ & + & - & + & - & - \\
\hline $\begin{array}{c}\text { C. } \\
\text { guilliemondii }\end{array}$ & - & + & - & - & + & $\mathrm{V}$ & + & - & + & + & + \\
\hline
\end{tabular}

Key: + = positive; $-=$ negative; $\mathrm{v}=$ variable.

not grow on this media, thus such organisms were not isolated.

Also the polymicrobial etiology (mixed Candida and bacterial infections) in 4 (1.5\%) of the HIV reactive subjects indicates the severity and the effect of immunosuppresion in this group.

\section{Conclusion}

Pulmonary candidiasis is a health problem among HIV positive patients in Calabar, Nigeria. Microexpress candida identification kit has been found to be useful in the identification of Candida to species level, as PCR is expensive and not easily assessable. Periodic study of pulmonary Candida infections among HIV infected patients is the present day's need, to know the changing pattern in incidence of Candida species.

\section{REFERENCES}

[1] A. Chakrabati and M. R. Shivaprakash, "Microbiology of Systemic Fungal Infections," Journal of Postgraduate Medicine, Vol. 51, No. 5, 2005, pp. 16-20.

[2] R. A. Calderone and W. A. Fronzi, "Virulence of Candida albicans,” Trends in Microbiology, Vol. 9, No. 7, 2001, p. 327. doi:10.1016/S0966-842X(01)02094-7

[3] B. K. Jha, S. Dey, M. D. Tamang, M. E. Joshy, P. G. Shivananda and K. N. Brahmadatan, "Characterization of Candida Species Isolated from Cases of Lower Respiratory Tract Infection,” Kathmandu University Medical Journal, Vol. 4, No. 3, 2006, pp. 290-294.

[4] E. Segal and D. Elad, “Candidiasis,” In: W. M. Scheld, D. C. Hooper and J. M. Hughes, Eds., Topley and Wilson's Microbiology and Microbial Infections, 10th Edition, Hodder Arnold ASM Press, Washington DC, 2005, pp. 479623.

[5] D. R. Soll, "Candida and Virulence: The Evolution of Phenotypic Plasticity,” Acta Tropica, Vol. 81, No. 2, 2002, p. 101. doi:10.1016/S0001-706X(01)00200-5

[6] Z. U. Khan, S. Ahmed, E. Mokaddas and R. Chandy, “Tobacco Agar, a New Medium for Differentiating Candida dubliniensis from Candida albicans,” Journal of Clinical Microbiology, Vol. 42, No. 10, 2004, pp. 4796-4798.

\section{doi:10.1128/JCM.42.10.4796-4798.2004}

[7] G. Diaz-Fuentes, C. Shin, E. R. Sy, M. Niazi and L. Menon, "Pulmonary Fungal Involvement in HIV-Positive Patients in an Inner City Hospital in New York,” The Internet Journal of Pulmonary Medicine, Vol. 7, No. 2, 2007, pp. 1531-2984.

[8] A. Usharani, M. Bharathi and C. Sandhya, "Isolation and Characterization of Candida Species from Oropharyngeal Secretions of HIV Positive Individuals," Nasza Dermatology Online, Vol. 2, No. 3, 2011, pp. 119-124.

[9] L. Y. Binesh and M. Kalyani, "Phenotypic Characterization of Candida Species and Their Antifungal Susceptibility from a Tertiary Care Centre,” Journal of Pharmaceutical and Biomedical Sciences, Vol. 11, No. 12, 2011.

[10] C. R. Juliana, "Phenotypic and Genotypic Identification of Candida spp. Isolated from Hospitalized Patients,” Revista Iberoamericana de Micología, Vol. 21, 2004, pp. 24-26.

[11] E. W. Koneman, S. D. Allen, W. M. Janda, P. C. Schreckenberger and W. C. Winn, "The Role of Microbiology Laboratory in the Diagnosis of Infectious Disease: Guidelines to Practice and Management,” In: R. P. Pfeiffer and B. C. Magnus, Eds., Color Atlas and Text Book of Diagnostic Microbiology, 5th Edition, Lippincot Press, New York, 1997, p. 69.

[12] B. A. Forbes, D. F. Sahm and A. S. Weissfeld, "Laboratory Methods in Basic Mycology,” In: Bailey and Scott's Diagnostic Microbiology, 11th Edition, Mosby, St. Louis, 2002, pp. 711-798.

[13] L. S. Garcia, G. W. Procop, G. D. Roberi and R. B. Thompson, "Overview of Conventional Methods for Bacterial Identification, Chapter 13,” In: B. A. Forbes, D. F. Sahm and A. S. Weissfeld, Eds., Bailey and Scott's Diagnostic Microbialogy, 10th Edition, Mosby, 1998, pp. 167-181.

[14] M. Cheesbrough, "Medical Laboratory Manual for Tropical Countries: Microbiology Vol. 2. Butterworth-Heinemann Ltd.," University Press, Cambridge, 1995, pp. 248273.

[15] G. S. De Hoog, J. Guarro and M. E. Grauer, "Atlas of Clinical Fungi,” 2nd Edition, Centraalbureauvoor Schimmelcultures, Baarn, 2000.

[16] H. S. A. Aluyi, F. D. Otajevwo and O. Iweriebor, "Incidence of Pulmonary Mycoses in Patients with Acquired Immunodeficiency Diseases," Nigerian Journal of Clinical 
Practice, Vol. 13, No. 1, 2010, pp. 78-83.

[17] G. St. Germain, M. Laverdiere and R. Pelletier, "Prevalence and Antifungal Susceptibility of 442 Candida Isolates from Blood and Other Normally Sterile Sites: Results of a 2 Year (1996-1998) Multicentre Surveillance Study in Quebec, Canada,” Journal of Clinical Microbiology, Vol. 39, No. 3, 2001, pp. 949-953. doi:10.1128/JCM.39.3.949-953.2001

[18] P. Bhalla, "Non Mycobacterial and Bacterial Infections in HIV/AIDS,” In: U. K. Baveja and J. Sokhey, Eds., Manual on Laboratory Diagnosis of Common Opportunistic Infections Associated with HIV/AIDS, National Institute of Communicable Diseases, New Delhi, 2002, pp. 100118.

[19] L. A. Shailaja, L. A. Pai, D. R. Mathur and V. Lakshmi, "Prevalence of Bacterial and Fungal Agents Causing Lower Respiratory Tract Infections in Patients with HIV Infection,” Indian Journal of Medical Microbiology, Vol. 22, No. 1, 2004, pp. 28-33.

[20] N. Koffi, A. Ngom, B. Kouassi and M. Tchamran, "Bacterial Lung Disease from Common Bacteria during HIV Infection in African Adults Hospitalized in Abidjan, Cote d'Ivoire," Bulletin de la Societe de Pathologie Exotique, Vol. 90, No. 5, 1997, pp. 370-372.

\section{List of Abbreviations}

\section{Abbreviation/Symbol Meaning}

HIV: Human immunodeficiency syndrome

AIDS: Acquired immune deficiency syndrome

ART: Antiretroviral therapy

DOTS: Directly Observed Treatment Short

Course

KOH: Potassium hydroxide

SDA: Sabouraud Dextrose Agar

CMA: Corn meal agar

BHIA: Brain Heart Infusion Agar

${ }^{\circ} \mathrm{C}$ : Degree Celsius

$\chi^{2}$ : Chi Square

mg: Milligramme

ml: Milliliter

L: Litre

$\mu \mathrm{l}$ : Microliter

g: Gram

\%: Percent

No: Number

TB: Tuberculosis 